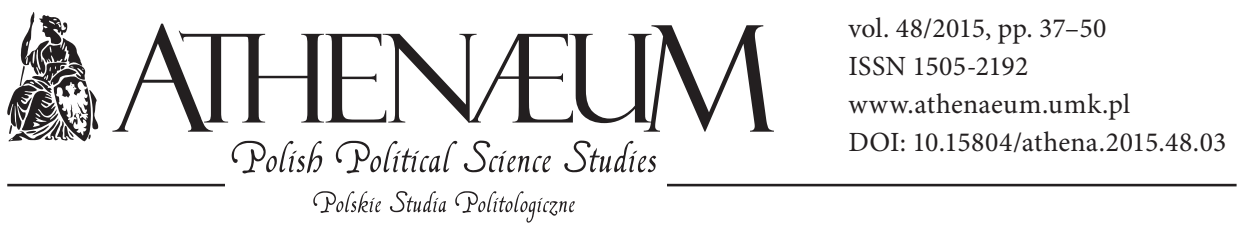

\title{
RECONCILING INCREMENTALISM WITH POLICY CHANGE. THE PUNCTUATED EQUILIBRIUM THEORY IN POLITICAL SCIENCE
}

\author{
Tomasz Czapiewski*
}

\begin{abstract}
The aim of this article is to explain current definition and application of punctuated equilibrium theory, which is as influential as any conceptual framework concerning policy process in political science, stimulating thought and research over the last two decades. Baumgartner and Jones borrowed the concept from studies of the evolution of species, but - as author shows - without operationalized definition, and turned it into a metaphor that can have mostly pedagogical use.

Author explains how punctuated equilibrium is useful for analyzing policy change in political systems other than the United States, but in the European political systems, political parties and their preferences must be taken into account. It is also presented how punctuated equilibrium is in fact a much-improved version of the incrementalism theory, rather than an application of biological insights to politics. Author differentiate successful application of the punctuated equilibrium in the description of the policy process from the explanation of Baumgartner and Jones about how those identified patterns in modern democracies were caused.
\end{abstract}

\section{- KEYWORDS}

theory of politics, policy process, public policy, policy change, punctuated equilibrium theory

* University of Szczecin, Institute of Political Science and European Studies. 


\section{INTRODUCTION}

The theory of punctuated equilibrium was originally developed on the basis of studies of the evolution of species, formulated in 1972 by Niles Eldredge and Stephen Jay Gould in response to the gradualism. It is unusual, as most of the theoretical approaches that political science has incorporated originated from other social sciences - concepts such as inquiry-principal-agent theory from economics, culture from anthropology, socialization from psychology and sociology, and so on (Prindle 2012: 39).

The assumption of punctuated equilibrium was that species arise very quickly, almost abruptly. This concept entered political science in the $1990^{\mathrm{s}}$ - at first to explain patterns of the American voting and elections (Prindle 2012: 28). The theory of punctuated equilibrium in political science attempts to explain the simple observation - policy processes are characterized by stability and incrementalism, but incidentally result in a change on a grand scale. However, Baumgartner and Jones cut the concept of Gould's punctuated equilibrium away from its operationalized definition and turned it into a metaphor that can have mostly pedagogical use (Prindle 2012: 32).

Far-reaching changes are taking place in one or more policy areas, when public understanding of current political issues is revised. Policies and government strategies are sometimes dramatically changed, but in most cases function in a manner similar to those from the past. Political area is understood as identical to the concepts of policy subsystem, i.e. section of public policy characterized by distinctiveness and a minimum internal cohesion, e.g. the area of health policy or the area of environmental protection.

The ambition of the theory of punctuated equilibrium is to explain both stable and inconsistent elements in the policy process, while according to the authors, earlier theories and models were designed or effective only in explaining one of the above elements. It can be argued that the theory of punctuated equilibrium has acquired status of commonly perceived as useful in explaining the essence of the policy process. However, in the Polish science it is used relatively seldom. It is only broadly mentioned by Ewa Nowak (2014: 77-94), although, this notion is translated into Polish in the way that is difficult to accept.

Incrementalism was the dominant paradigm for the description of the policy process from the $1950^{\text {s }}$ to the $1980^{\text {s }}$ (Dahl, Lindblom 1953). It was argued that policymakers do not survey all the possible choices to achieve the most desired results. The weakness of the theory of incrementalism was revealed during this 
first broader empirical research that tried to turn incrementalism into an empirical theory reinforcing Lindblom's view. While conducting an analysis of the functioning of government agencies, Davis, Dempster and Wildavsky recognized the existence of decision rules strengthening the incrementalism, but also two types of non-incremental changes: temporary discontinuation of applying the rules or the introduction of completely new rules in the place of earlier ones (Davis, Dempster, Wildavsky 1966). The process of creating a budget is usually an incremental, though capable of responding to the needs of the economy and society, but only when it produces an adequate pressure on the participants in the process (Davis, Dempster, Wildavsky 1974: 427). Incrementalism does not enable to explain the phenomenon of radical changes in the political subsystems. It even excludes their existence, which is in contradiction to the empirical research or even the routine observation.

In their book, Baumgartner and Jones (1993) investigated a variety of policy areas through decades, and each time found a pattern of relatively long periods of stability broken by relatively short periods of significant activity, or in other words long-term incrementalism broken by short-term punctuations. From this time on, independently situated scholars frequently conducted empirical research demonstrating this ubiquitous pattern of policymaking. It is reasoned to say that punctuated equilibrium has been as influential as any conceptual framework in political science stimulating thought and research over the last two decades.

It could be observed that policy process in a routine manner usually leads to changes on a limited scale, while in larger intervals is a subject to shocks resulting in a radical departure from previous political mechanisms. And the existing policies had been already made in several research frameworks in the United States, although without convincing empirical proof. The ambition of the theory of punctuated equilibrium was also to extend the above observation basing it on a double foundation - institutionalism at the macro level and bounded rationality at the micro level. Punctuated equilibrium emphasized one assumption of bounded rationality - the short span of human attention, which afflicts political authorities as well as individuals. In the theory of punctuated equilibrium, particular consideration was given to the previously neglected elements: defining political problems and agenda-setting. Process of changing the definitions in the public discourse, and advancement and fall of political problems on the political agenda reinforces or undermines the existing policies (True, Jones, Baumgartner 2007: 156). Therefore, the theory of punctuated 
equilibrium is also sometimes described as the innovative combination of two approaches to the public policy - focusing on "policy communities", and those focusing on the process of agenda-setting (Cairney 2012: 175-176). Subsystem approach suggests that interest groups operate in a more restricted setting than traditional group theorists would present, acting at the meso-level of the polity in decision-making systems organized around discrete programs and issues (Worsham 1998: 486).

The paper is organized as follows. To begin with, the relations between political change and bounded rationality are explored. Simon's concept of bounded rationality is the key assumption in the punctuated equilibrium's explanation of policy process. Then, the two important phenomena in the theory are analyzed: policy monopoly and policy image. Both are crucial in maintaining stability and limiting changes. Before concluding, there is a review of the most interesting developments in the application and adaption of the theory in political science.

\section{POLITICAL CHANGE AND BOUNDED RATIONALITY}

Herbert Simon $(1957,1991)$ expanded the concept of bounded rationality distinguishing two types of information processing in decision-making: serial and parallel. The individual has only the ability to serial processing of information, i.e. can consciously devote attention to only one thing at a time. Another issue may be the subject of analysis and decision only after the (successful or not) attempt to cope with the previous issue. Organizations demonstrate greater diversity - some process individual information in a serial manner, but others are capable of parallel processing - dealing with many issues at the same time. Bounded rationality, understood in short as the awareness of cognitive limitations that policy-makers are subject to, was already the basis for the theory of incremental deciding within the framework of the budget process (Wildavsky 1964).

Originally, political systems at the macro level - similarly to the individuals have only the ability of serial processing. The creation of partially autonomous policy subsystems allowed to engage system as a whole in parallel processing. Dozens, hundreds, or even thousands of issues of concern may be subject to analysis and decision at the same time within the appropriate expert communities (Jones 2001). Delegating issues to subsystem does not rule out changes 
- group negotiations, coordination of interests and responding to a changing environment of a subsystem result in modifications, although to a limited extent. Political serial processing excludes radical change.

When parallel processing model in the specific subsystem ceases to function, the issues become the subject of serial processing, which is the domain of macrolevel political system - identified in this paper as the political authorities on the highest level (usually one or two-chamber parliament and the government or president). Most commonly, political authorities deal with one, at most, several problematic political issues at the same time. In such conditions, these must be the issues of great importance, occupying top positions on the political agenda. In the theory of punctuated equilibrium, factors that affect the elevation of the issue to the top of the agenda are: the emergence of new, influential political actors interested in the issues of concern, change of the issue definition and increased media and public attention (True, Jones, Baumgartner 2007: 159). Moving issue to the top positions on the political agenda at the system level is necessary, but not sufficient for the radical policy change. The decision making process, initiated by changes in the agenda, is long and often unpredictable - it may end without a decision, understood in a positive way, or with a decision distant from the expectations of political actors that were involved as advocates for change. The individual decision-making constantly use the same attributes that allows to structure alternatives until it is externally motivated to modify attributes (Jones 2001).

Transformation of the environment is a process with many obstacles. Involvement in political decision-making process raises transaction costs. Actors in the political system must bear these costs in order to respond to signals from the environment, which also tend to be vague and ambiguous. Costs can be twofold: cognitive - political actors must recognize the signal in order to be able to devote their attention, interpret signal and prepare solutions; and institutional - where the rules of the political system are usually thought to maintain the stability of the system (Jones, Baumgartner 2005). As a consequence, the issue is more probable to reach political agenda than to result in a particular political action. Indicators of agenda-setting, such as draft legislation, the deliberations of parliamentary committees and media reporting, are of much less leptokurtic character than the basic measure of the outputs of the political system (budget). Similarly to the original version of the Advocacy Coalition Framework, in the punctuated equilibrium theory radical change has its source outside of the subsystem, while small changes are routinely made within the subsystem. Periods 
of change are a necessity for the political system that allow for adapting to the environment and preventing from transformation into rigid Leviathan (True, Jones, Baumgartner 2007: 157).

In many cases, crises such as natural disasters initiate the policy process by focusing attention of the political authorities, media and public on issues that are far down on the agenda. Such initiating events may also become a dramatic symbol of the problems that have already begun to arouse more interest (Baumgartner, Jones 1993: 140). Environmental disasters like oil spills, etc., have had such significance in the last decades.

Baumgartner and Jones recently introduced the general notion of friction, indicating why political actors react disproportionally to incoming information (Jones, Baumgartner 2005; Jones, Sulkin, Larsen 2003). Friction implies that political actors sometimes do not react at all, but at other times overreact and suddenly pay a large amount of attention to the issue (Walgrave, Varone 2008: 391-392).

\section{POLICY MONOPOLY}

Discussion on political issues is usually carried out within the policy subsystems, created by the substantive criteria, not at the macro level. Each of the subsystems can be dominated by one interest group or may become a field of competition between a few interest groups. Borders are not fixed - subsystem may disintegrate and be absorbed by another subsystem, or a part of subsystem may develop into a new subsystem. If one interest group and one category of interests dominate the subsystem, such situation is referred to as the political monopoly.

Political monopoly is built by a community of experts/professionals operating within the bureaucracy, parliamentary committees and interest groups, working outside of the sphere of public and media interest. This community decides on more or less important issues within the subsystem. Sometimes, however, certain issues "light up" - in terms of Baumgartner and Jones - and become a subject of attention of the macro level political system (True, Jones, Baumgartner 2007: 158). Long periods of stability (balance) and periods of radical change (punctuations) within the same institutional structure can be explained by the process of agenda-setting. It is also worth noting that although the individual events could begin the period of radical change, that period does not have to be short- 
lived - once losing its equilibrium, subsystem may not recover for many years (Baumgartner, Jones 1993: 280-281).

Policy monopoly in the terms of the punctuated equilibrium theory can be described with the help of the classification of political networks created by Rhodes and Marsh (1992: 251). Continuum of different types of relations between interest groups-public authorities extends between the two extremities: the policy community and the issue network. In the issue network, number of members is significant, barriers to entry are low, meetings occur on an irregular basis, relationships are unstable and there is often presence of a conflict. Policy monopoly in punctuated equilibrium is similar to the policy community: it consists of few members (most are excluded), mutual relations are close and stable, meetings between the members of the community are held often, and members of the monopoly share, at least at a basic level, a common understanding of policy problem and conviction about the best methods of solving it. One of the conditions for membership in the monopoly is to follow the basic rule potential disputes are resolved within the community, not outside of it. Member of the monopoly should also support policy implementation. Policy monopoly, although closed and trying to "hide" from the eyes of the media and the public, is not synonymous with the so-called club politics or iron triangle, as the policy process was commonly described in the postwar period (Heclo 1978: 88). In this case, it refers to narrow elite at the macro level, rather than monopolies at the subsystem level.

Institutional divisions and overlapping competencies between institutions lead to a specific political dynamics between subsystems and macropolitics of parliament and the president. The inter-institutional dynamics usually paradoxically blocks the possibility of change, but sometimes has contrary effects and increases the scale of change. Shifts in the configuration of the dominant interests in the subsystem require the mobilization of considerable resources. That is not easy, but if happens, political actors, who have supported the existence of the status quo (directly or indirectly) so far, possess the motivation to engage in the process of change, accelerating and intensifying it. In countries such as the United States - with a federal structure, deep separation of powers and obscure jurisdictions at the same time - the number of political actors, who may be involved in the operation of the subsystem is significant, which further increases the size change (Baumgartner, Jones 1993). As Kingdon (1995) stated, there are many different policy entrepreneurs, many possible policy venues, and always many competing policy images available in the "primeval policy soup". 
Political opponents can choose one of three strategies to remove the political monopoly of the subsystem. They can try to focus public attention and lead to interference of political authorities from the highest level into the subsystem. Alternatively, they may throw a kind of challenge to a monopoly within the subsystem by modifying the dominant political image. Often, however, the only real option is to search for appropriate decision-making venue. They strive, by trial and error, to find a venue that will be more sympathetic towards their demands and interpretations. As growing competences of public authorities and tendencies of decentralization increased the number of decision-making venues, it has become more difficult for the political monopoly to maintain isolation from the environment (Baumgartner, Jones 1993: 43). It must be added, that not only interaction between policy images and policy venues brings about major policy change - actors within venues also determine whether change will be produced (Walgrave, Varone 2008: 387).

Punctuated equilibrium theory does not exclude the far-reaching diversity in terms of mechanisms of functioning of the various subsystems. Worsham (1998: 487-489) identified three basic types of subsystems, based on perceived differences in the ability of actors within the subsystem to block demands for change: dominant coalition, transitory coalition, and competitive coalition. Dominant coalition politics are similar to the classic iron triangle, in which legislators, government personnel, and special interests together decide about the public policy in a particular policy area. Transitory coalitions are created through the fracture of the dominant coalition into several proto-coalitions, which happens when the hidden interests of some members of a dominant coalition become more important to them than the interests they share in common with other members. Competitive coalition politics occur when traditionally dominant interests are challenged by a new coalition. In some cases, previously minority interests are able to achieve the control of the subsystem, in others, the new coalition involves outsiders from another subsystem.

\section{POLICY IMAGE}

Policy monopoly is not only the institutional structure dominant in the political subsystem. Monopoly to legitimize its position needs ideas or the so-called policy image. In the theory of punctuated equilibrium it is not personal; it does not concern the individual politician, but problematic issues and ways of their imag- 
ing for the media and the general public. Policy image should be predisposed to a simple and direct communication to the environment (Baumgartner, Jones 1993: 5). The political balance in the policy area is the result of the dominance of a particular policy image, supported by the power of a public authority and stabilized relations between the political forces (Baumgartner, Jones 1993: 19).

Explanation of the theory of punctuated equilibrium also refers to the feedback model (Baumgartner, Jones 2002). In periods of balance there is a negative feedback - a power of policy monopoly and attractiveness of the policy image created by the monopoly block the subsystem's responsiveness to the requests for changes. In periods of radical change there is a positive feedback - small changes in the objective conditions relating to issue may lead to a radical change of policy, if it is at the macro level of political agenda. Here, the authors suggest an analogy to earthquakes - caused by the accumulation of small changes inside the globe. Ultimately, it is one minor change within the Earth that causes a drastic movement of tectonic plates beneath the Earth's surface and natural disaster.

Policy image is made up of a core based on empirically verifiable information and additional element that allow image to influence the emotions of the recipient. Each policy or political agenda is multifaceted and affects thousands of people in different ways. Therefore, if the policy is associated with one political image and has a generally positive meaning, it is a key to success of the policy monopoly. The image of political issues highlighting its technical, routine nature and incomprehensibility for non-specialists, discourages the participation of external actors and limits media coverage and public opinion attention. Therefore, it is also particularly attractive to political monopoly. Similarly desired is the image which indicates that the political problem was solved in principle and only specific elements relating to implementation remained to be realized.

Opponents of the existing political monopoly usually try to present a far different policy image of the issue. For example, in the past, in the area of energy policy, monopolies effectively depicted the image of cost efficiency and availability of energy produced from coal. In the last decades, opponents were able to present the image of atmospheric pollution resulting from coal processing, weakening the existing monopoly. It is important for opponents to appeal to universally accepted values, which can reach the attention of the environment. In the 90s, the list of the most important values for the US citizens included: progress, patriotism, sovereignty understood as an independence from external domination, justice and economic growth (Baumgartner, Jones 1993: 7). In other 
political systems, catalogs of such values are shaped differently, and all these catalogs will be subject to change over time.

The change of political image in the punctuated equilibrium theory is a prerequisite for radical change (True, Jones, Baumgartner 2007: 161-162). That is explained by changes in attention - cognitive limitations result not only in reducing the number of issues that an individual can deal with. He is also not able to fully understand multi-element and permanently changing issues. The individual focuses on the selected, most significant element or its attribute. If the part or the whole of an attribute that is the focus of attention changes, the whole perception of the issue changes as well. That leads to a change of the methods of dealing with the issue. Changing the image means highlighting the most important elements or attributes of problematic issues, which are different from the previous ones. Cognitive limitations allowing political actors to perceive the issue only through the prism of one or more of the most important features result in a radical transformation of the interpretation of the problem and, consequently, in a radical change. The fact that individuals or organizations change earlier decisions, sometimes even completely withdrawing from them, does not result from sudden drastic changes in preferences or irrationality understood as the inability to make decisions according to one's own preferences (Jones 2001).

Dissemination of the new image can attract new political actors to the subsystem. More important political venues in the political system (in countries with federal or decentralized structure, as well as within the European Union) lead to more opportunities for the political entrepreneurs. If the federal government is not responsive to the presented expectations, there is a possibility of attempt to place it on the agenda of state (True, Jones, Baumgartner 2007: 162), region and the European Union, particularly since each of decision-making venues has a specific set of rules of conduct and different levels of openness to the participation of outside actors. It is frequently called "venue shopping".

The key element of most policy images and political problems is the answer to the questions - who is to blame for the emergence of the problem and who is responsible for solving the problem. Rarely, there is a general consensus that allows for a clear answer. Given the limited capacity of attention, struggle for dominance of the policy image between groups within a subsystem is not a question of proving that opponent's arguments are wrong, but is rather a question of drawing attention to other arguments, facts, or attributes. 


\section{CRITICAL RECEPTION OF PUNCTUATED EQUILIBRIUM}

During the evolution of punctuated equilibrium it was noted that policy change can be caused by variety of factors: elected officials, legislative committees, wars, new technologies and scientific changes, radical economic change, and reformist mobilizations by interest groups and coalitions opposed to policy monopolies (Repetto 2006; Givel 2010). Similarly diverse are factors contributing to the resistance of punctuations, which have been identified as: policy entrepreneurs, courts and rule of law, policy monopolies, bounded and not comprehensive rationality, lack of acceptance of new policy ideas tied to a public policy, and the fragmented political system in which only selected political jurisdictions may adopt significantly new legislation (Givel 2010: 188)

Worsham (1998: 486) noticed that before interest groups attempt to move an issue from the realm of parallel processing (sub-systems) to the realm of serial processing (the macro level) (Baumgartner, Jones 1993: 20), they engage in efforts to reshape the realm in which parallel processing occurs. These efforts, as well as additional factors, may cause particular subsystem equilibrium to waver - to move from one variant to another in an attempt to accommodate new pressure - that proves that subsystems are more flexible and varied than previously recognized. Therefore, the notion of wavering equilibrium was presented by Worsham. Prindle declared a proposition to rename the concept - "punctuated incrementalism" instead of "punctuated equilibrium" - because in his view the theory of policymaking articulated by Baumgartner and Jones is actually a much-improved version of the incrementalism theory, rather than an application of biological insights to politics, as proved earlier by Howlett and Migone (2011). Two aspects should be differentiated - descriptive and explanative. Successful application of the punctuated equilibrium in the public policy (descriptive model) does not necessarily prove the explanation of Baumgartner and Jones about how those identified patterns in modern democracies were caused (causal explanation) (Prindle 2012: 37-38). There are scientific studies, i.e. Pacific Northwest forestry policy, U.S. state tobacco policy, or U.S. auto efficiency policy proving that substantial outside alteration does not always lead to punctuation (Cashore, Howlett 2007; Givel 2010). Givel (2010: 196) even suggested that this warrants a revised description of the current "public policypunctuated equilibrium syllogism".

It must be also taken into the account that the political system of the United States is one of a kind open and pluralist. Punctuated equilibrium is useful for 
analyzing policy change in other political systems (Baumgartner, Jones 1993, 2009; Breunig, Koski 2006; Jones, Sulkin, Larsen 2003; Repetto 2006; Wood 2006, Worsham 1998), but further conditions should be added. In the European political systems, political parties and their preferences must be taken into account, or as Walgrave and Varone put it directly: "no parties, no change" (Walgrave, Varone 2008: 388-389). Focusing event, new image, new policy venue and much attention do not inevitably produce change. In European systems, there is a need for a suitable policy venue in which parties could play their usual role and intermediate in an elite compromise that shall translate into a major policy change. Moreover, probability of a policy change may be influenced by the date of general elections. Parties are autonomous actors and can act as veto players, defending their preferences, even those, which are against the mainstream (Walgrave, Varone 2008: 391-392) - and it was proved that shifting preferences is not easy for parties (Walgrave, Varone, Dumont 2006). Parties do not wait for external factors to induce changes - there are planned and gradual changes through the electoral cycle. In 2009, Baumgartner and Jones (2009) revised the theory and stated that punctuated equilibrium can occur through "disruptive dynamics" created by interaction between political parties, interest groups, elected officials, and legislative committees.

\section{CONLUSIONS}

Focusing on political institutions, mobilization of interests and bounded rationality, punctuated equilibrium helps to explain the dynamics of interactions between institutions and groups. Taking into account the limitations of public institutions, constantly increasing public competences and an endless amount of problems looking for a place on the political agenda, punctuated equilibrium builds a model of multi-level political system of comprehensive internal connections.

Political system is able to function thanks to the creation of the partially autonomous policy subsystems that allow to engage system as a whole in parallel processing. Stability in the subsystems is preserved by policy monopoly which consists of a few members (most are excluded), where mutual relations are close and stable, meetings between the members of the community are held often, and members of the monopoly share a common understanding of policy problem. What is the most interesting - policy monopoly is closed and trying to "hide" 
from the eyes of the media and the public. Interplay between policy monopoly and policy image is crucial - ways of imaging problematic issues for the media and the general public allow to keep macro-system away from the subsystem.

As pointed in this article, punctuated equilibrium is useful for analyzing policy change in political systems other than the United States, but in the European political systems, political parties and their preferences must be taken into account. Although punctuated equilibrium was created in opposition to the previously dominating theory of incrementalism, that is, in fact, a much-improved version of this theory (long-term incrementalism broken by short-term punctuations), rather than an application of biological insights to politics. Analyzing the theory of punctuated equilibrium we have to differentiate successful application of the punctuated equilibrium in the description of the policy process from the explanation of Baumgartner and Jones about how those identified patterns in modern democracies were caused.

\section{REFERENCES:}

Baumgartner F., Breunig C., Green-Pedersen C., Jones B., Mortensen P., Nuytemans M., Walgrave S. (2009). Punctuated Equilibrium in Comparative Perspective. "American Journal of Political Science" 53 (3).

Baumgartner F., Jones B. (1993). Agendas and Instability in American Politics. Chicago: University of Chicago Press.

Baumgartner F., Jones B. (2002). Positive and Negative Feedback in Politics. [in:] Policy Dynamics. F. Baumgartner, B. Jones (eds.). Chicago: University of Chicago Press.

Baumgartner F., Jones B. (2009). Agendas and Instability in American Politics (2 $2^{\text {nd }}$ ed.). Chicago: University of Chicago Press.

Breunig C., Koski C. (2006). Punctuated Equilibria and Budgets in American States. "Policy Studies Journal" 34 (3).

Cairney P. (2012). Understanding Public Policy: Theories and Issues. Edinburgh: Palgrave Macmillan.

Cashore B., Howlett M. (2007). Punctuating Which Equilibrium? Understanding Thermostatic Policy Dynamics in Pacific Northwest Forestry. "American Journal of Political Science" 51 (3).

Dahl R., Lindblom C. (1953). Politics, Economics, and Welfare. New York: Harper \& Brothers.

Davis O., Dempster M., Wildavsky A. (1966). A Theory of the Budgetary Process. "The American Political Science Review" 60 (3).

Davis O., Dempster M., Wildavsky A. (1974). Towards a Predictive Theory of Government Expenditure: U.S. Domestic Appropriations. "British Journal of Political Science" 4 . 
Givel M. (2010). The Evolution of the Theoretical Foundations of Punctuated Equilibrium Theory in Public Policy. "Review of Policy Research" 27 (2).

Heclo H. (1978). Issue Networks and the Executive Establishment. [in:] The New American Political System. A. King (ed.). Washington: American Enterprise Institute.

Howlett M., Migone A. (2011). Charles Lindblom is Alive and Well and Living in Punctuated Equilibrium Land. "Policy and Society" 30.

Jones B. (1994). Reconceiving Decision-Making in Democratic Politics: Attention, Choice and Public Policy. Chicago: University of Chicago Press.

Jones B. (2001). Politics and the Architecture of Choice. Chicago: University of Chicago Press.

Jones B., Baumgartner F. (2005). The Politics of Attention. Chicago: University of Chicago Press.

Jones B., Sulkin T., Larsen H. (2003). Policy Punctuations in American Political Institutions. "American Political Science Review" 97.

Kingdon J. (1995). Agendas, Alternatives and Public Policies. London: Longman.

Marsh D., Rhodes R. (1992). Policy Communities and Issue Networks: Beyond Typology. [in:] Policy Networks in British Government. D. Marsh, R. Rhodes (eds.). Oxford: Oxford University Press.

Nowak E. (2014). Ustanawianie agendy politycznej (policy agenda-setting) jako nurt badań politologicznych. "Athenaeum. Polskie Studia Politologiczne" 43.

Prindle D. (2012). Importing Concepts from Biology into Political Science: The Case of Punctuated Equilibrium. "The Policy Studies Journal" 40 (1).

Repetto R. (2006). Introduction. [in:] Punctuated Equilibrium and the Dynamics of U.S. Environmental Policy, R. Repetto (ed.). New Haven: Yale University Press.

Simon H.A. (1957). A Behavioral Model of Rational Choice. [in:] Models of Man, Social and Rational: Mathematical Essays on Rational Human Behavior in a Social Setting. H.A. Simon (ed.). New York: Wiley.

Simon H.A. (1991). Bounded Rationality and Organizational Learning. "Organization Science" 2 (1).

True J., Jones B., Baumgartner F. (2007). Punctuated Equilibrium Theory. Explaining Stability and Change in Public Policymaking. [in:] Theories of the Policy Process. P. Sabatier (ed.). Boulder: Westview Press.

Walgrave S., Varone F. (2008). Punctuated Equilibrium and Agenda-Setting: Bringing Parties Back in: Policy Change After the Dutroux Crisis in Belgium. "Governance: An International Journal of Policy, Administration, and Institutions" 21 (3).

Walgrave S., Varone F., Dumont P. (2006). Policy With or Without Parties? A Comparative Analysis of Policy Priorities and Policy Change in Belgium, 1991 to 2000. "Journal of European Public Policy" 13 (7).

Wildavsky A. (1964). The Politics of Budgetary Process. Boston: Little Brown.

Wood R.S. (2006). The Dynamics of Incrementalism: Subsystems, Politics, and Public Lands. "Policy Studies Journal" 34 (1).

Worsham J. (1998). Wavering Equilibriums. Subsystem Dynamics and Agenda Control. "American Politics Research" 26 (4). 